\title{
Devenir otro, devenir pariente: las masateadas yaminahua (Amazonía peruana)
}

\author{
Laura PÉREZ GIL \\ Departamento de Antropologia, Universidade Federal do Paraná \\ laurapg@ufpr.br \\ Miguel CARID NAVEIRA \\ Departamento de Antropologia, Universidade Federal do Paraná \\ mikelcn@yahoo.com.br
}

Recibido: 10 de enero de 2013

Aceptado: 24 de enero de 2013

\section{RESUMEN}

Durante las masateadas los yaminahua se reúnen y consumen grandes cantidades de masato, la bebida fermentada de yuca que da nombre a esas fiestas. La música, el baile y la participación de los madereros que trabajan río arriba marcan estas reuniones durante las cuales las familias, dispersas en el día a día en los caseríos distribuidos a los largo del curso fluvial, se juntan para divertirse, bailar y flirtear. Las masateadas parecen operar como una especie de modelo reducido sociológico: en ellas, los principios centrífugos y centrípetos de la dinámica social yaminahua se muestran de forma condensada y en acción. Si de un lado están plenamente operativos los valores que unen -la alegría, la generosidad, la voluntad de juntarse con parientes y personas afines-, de otro lado se manifiestan con especial intensidad las líneas de fractura y conflicto parcialmente obviadas en lo cotidiano, la tristeza y la separación. En este texto examinamos cómo las masateadas construyen y expresan dichas relaciones, constituyéndose en uno de los espacios (y momentos) paradigmáticos de su confluencia.

Palabras clave: Yaminahua, memoria, mestizo, masato.

\section{Becoming Other, Becoming a Relative: The Masato Feasts among Yaminahua (Peruvian Amazon)}

\begin{abstract}
During the masateada festivities the Yaminahua get together to consume mass quantities of masato, the fermented manioc-based drink that gives the festival its name. The music, dancing, and participation of loggers who work up the river mark these encounters in which families, who would normally be busy with their day-to-day chores in the housing complexes distributed along the flow of the river, get together to have a good time, dance, and flirt. The masateadas seem to function as a kind of reduced sociological model: in these festivities, the centrifugal and centripetal principals of Yaminahua social dynamics may be seen in action in a condensed form. If, on the one hand, the values uniting this group are fully operational -joyfulness, generosity, the desire to get together with family members and friends- on the other, points of fracture and conflict only partially obvious in daily life, such as sadness and separation, become manifest with special intensity. This text examines how the masateadas construct and express such kinds of relationships, thus constituting one of the paradigmatic spaces (and moments) of their confluence.
\end{abstract}

Key words: Yaminahua, memory, mestizo, masato.

Sumario: 1. ¿¿Hay masaaaatoooo?! 2. Acelerando relaciones. 3. Diferencia, mestizaje y transformación. 4. Memorias intensas y extensas. 5. Conclusiones. 6. Referencias bibliográficas.

\section{1. ¿¿Hay masaaaatoooo?!}

«i¿Hay masatoooo?!» es el grito de guerra del buen bebedor yaminahua ${ }^{1}$ Lo oímos muchas veces cuando los yaminahua anunciaban su llegada al lugar de encuentro

${ }^{1}$ Ese grito es proferido sólo por los hombres. Aunque las mujeres consuman también grandes cantidades de masato como los hombres, hasta embriagarse, no manifiestan la avidez masculina por la bebida. Recordemos que aunque todos sean consumidores, son ellas las que producen y ofrecen la bebida. 
y sus expectativas, jocosos y provocadores, ante la perspectiva de varias horas, o días, de fiesta.

Fue lo que pasó pocas semanas después de que llegásemos a Raya ${ }^{2}$, cuando Wëdëatxi y algunos niños vinieron a buscarnos a nuestra casa para invitarnos: «iVengan, en casa hay masato!». Cuando llegamos a casa de Wëdëatxi, la penúltima en la parte más baja de la aldea, los yaminahua conversaban desinhibidos, adultos, jóvenes, viejos y niños compartiendo el mismo espacio festivo. Como habitualmente, el ambiente estaba marcado por una gran polifonía de voces, risas, gritos y bromas, y la dueña de la casa servía de una gran olla que contenía la bebida embriagadora. Con un tazón recoge el masato que deposita en otro tazón, el cual entregará a quien corresponda beber. Todos los presentes reciben el ofrecimiento, que no incluye ninguna invitación verbal especial, aparte del vocativo de relación habitual para llamar la atención si alguna persona estuviese distraída. A veces ni eso, y un toque en el hombro con el reverso de la mano para advertir que llegó su vez de beber es suficiente. Es de buen gusto ingerir de una sola vez el tazón entero, que se devuelve casi de inmediato a la dueña, y que ésta sea ágil en el suministro.

Aquel día, como sucedió en todas las masateadas posteriores, los bailes siguieron los ritmos de la tecnocumbia de moda. Una batería -o pilas si ninguna batería estuviese debidamente cargada-, un gran radiocasete y las grabaciones que los yaminahua consiguen cuando visitan la ciudad, o a través de los madereros, es la estructura básica que proporcionará animación sonora durante horas o días, dependiendo de la cantidad de bebida disponible. Las músicas, mezclas de ritmos folk, populares y pop, que relatan pasiones y dilemas arrebatadores, fracasos amorosos y nostalgias profundas, son bailadas por los yaminahua con intensidad y desinhibición, aunque sólo los más jóvenes se muevan al perfecto estilo mestizo. Con la música al máximo volumen y el masato haciendo efecto, las parejas se contonean con gracia en la pista de baile, algunas bien agarradas. En ocasiones se baila en el patio de la casa en que se consume el masato; en otras, en la propia casa, provocando el bamboleo intenso del suelo de madera de pona -resistente y muy flexible- sin que a nadie le preocupe mucho, a pesar del riesgo de venirse abajo -lo que vimos ocurrir en alguna ocasión-. Quien no baila, charla animadamente, en general hombres y mujeres separados. Las conversaciones giran en torno de cotilleos, rumores y, no raramente, de recuerdos de acontecimientos pasados. Cuando se habla de parientes ya fallecidos o que viven lejos, la melancolía puede manifestarse, lo que contrasta con el tono general de broma y diversión que prevalece en la fiesta.

Sin duda, la tecnocumbia es el estilo nacional preferido, aunque eventualmente se pueda oír también alguna cinta de huaynos, de estilo más melancólico y menos apto para el baile. Como veremos más adelante, las masateadas adquieren un carác-

${ }^{2}$ La comunidad nativa de Raya se encuentra situada en una amplia curva de leve inclinación en la orilla de la cabecera del río Mapuya, en el Departamento de Ucayali, Perú. La ciudad más cercana a la aldea es Atalaya, con la que se comunica sólo por medio fluvial. Normalmente las embarcaciones utilizadas por los yaminahua, pequeñas canoas de madera hechas por ellos mismos o compradas a los regionales, hacen ese trayecto en menos de dos o tres días, o bastante más en la época de seca, cuando el escaso caudal del río dificulta la navegación con motor, o si los viajantes deciden ir parando para visitar a los parientes y conocidos que habitan en las diversas comunidades (pobladas por ashaninka, amahuaca y mestizos) a lo largo del curso fluvial. 


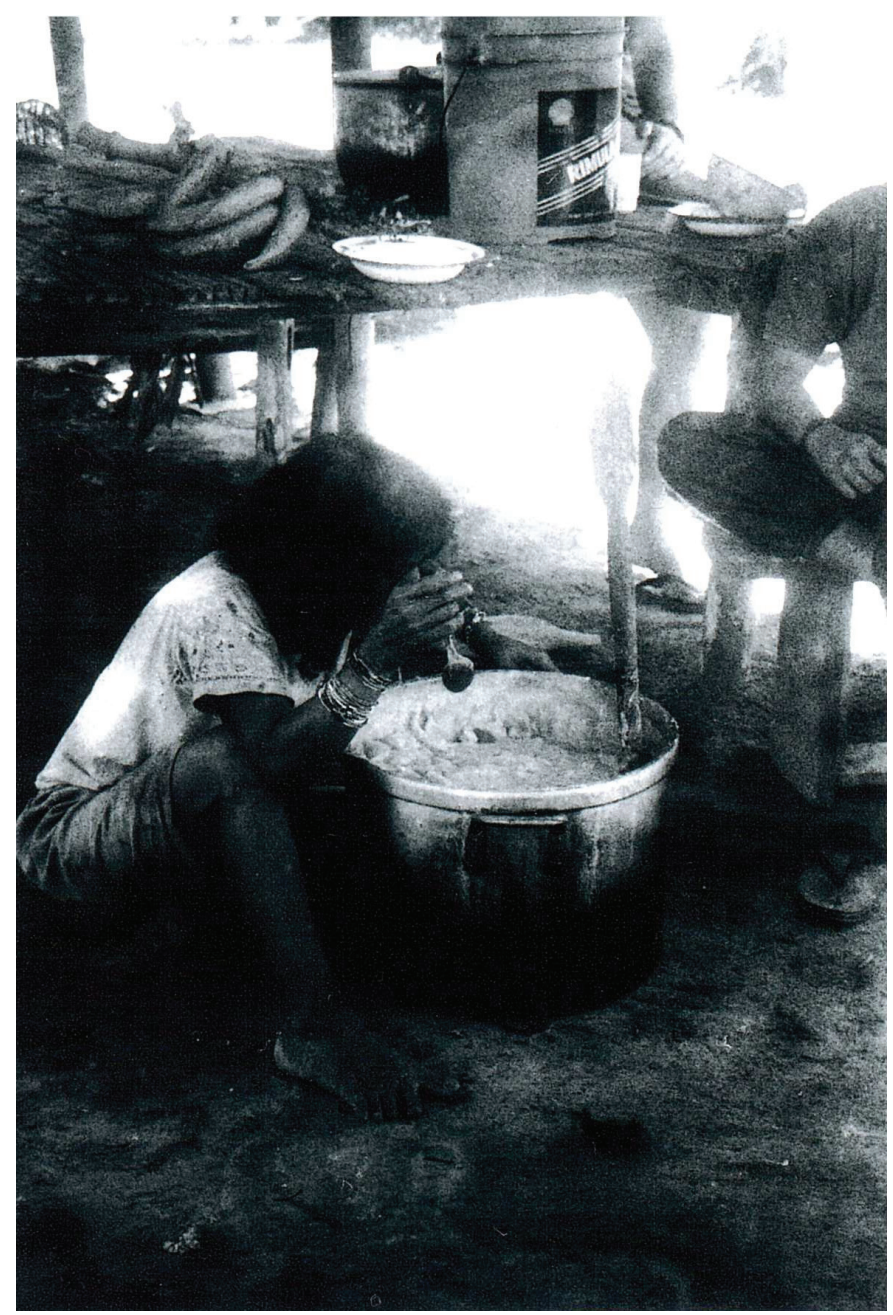

Figura 1: Mujer yaminahua haciendo masato.

(Foto: Miguel Carid y Laura Pérez, Raya, río Mapuya, 2001).

ter literalmente polifónico cuando al son de las tecnocumbias y a los gritos de los participantes más exaltados se suma alguna voz yaminahua interpretando un canto yama yama.

Las masateadas no tienen una periodicidad fija, pero cuando su preparación tiene como ocasión la celebración de una festividad nacional - como el Día de la Patria-, el trabajo se hace de forma colectiva. La mayoría de las veces, sin embargo, cada unidad familiar - generalmente, una madre y sus hijas, ya que corresponde a las mujeres hacer el masato- se encarga de la elaboración de su propio masato. De todas formas, incluso cuando se hace de forma individualizada, suele haber una cierta coordinación, ya que lo ideal es que haya gran cantidad de bebida fuerte para que la 
fiesta dure lo máximo posible. Sin masato no hay fiesta, y de hecho ésta sólo termina cuando se acaba la bebida.

El primer paso en el proceso de elaboración del masato es ir a la chacra ${ }^{3}$ a coger la yuca, tarea que puede ser hecha individualmente o en un grupo que reúna a varias mujeres. Ya en casa, se descasca, lava y trocea para poder hervirla adecuadamente. Para ello se usan grandes ollas de aluminio, uno de los enseres esenciales en cualquier casa yaminahua. Una vez cocinada, la yuca es machacada hasta que haya adquirido la consistencia de un puré denso. Llega aquí el paso fundamental: a medida que se va machacando, se masca parte de la masa que luego se devuelve a la olla para que fermente. En general, de esta tarea se encargan las adolescentes y mujeres más jóvenes. Aunque en el caso de los yaminahua nunca nos fue explicitado, la ingestión de bebidas fermentadas que fueron masticadas por jóvenes tiene una connotación erótica entre varios otros grupos pano ${ }^{4}$ y ello remite a la clara dimensión sexual que, como veremos, tienen las masateadas.

Dependiendo del tiempo de fermentación, el resultado es una bebida que oscila entre el gusto de un yogurt dulce y el de una cerveza embriagadora. Tres o cuatro días es el período habitual para que la bebida quede fuerte y amarga, cuya ingestión generalizada adquiere su máximo durante las masateadas. Cuando llega el momento de beber el masato, la masa se mezcla con agua, colándose adecuadamente para evitar los restos fibrosos de la mandioca.

En función del tipo de masato y de la forma de consumo podemos distinguir tres líneas principales de flujo del masato: el masato compartido en el ámbito doméstico; el masato ofrecido a los visitantes; y el masato consumido en las masateadas, que funciona como una suerte de síntesis de las dos anteriores, consumido y ofrecido en el mismo espacio y momento tanto para parientes como para visitantes diversos, mestizos, blancos e indígenas.

Durante las masateadas, la bebida fermentada de mandioca funciona como dádiva generalizada y su forma de consumo está marcada por el exceso. El líquido embriagador convoca a la participación general; un transitar colectivo de casa en casa al ritmo marcado por el sucesivo vaciamiento de las ollas, que puede durar algunas horas o varios días, dependiendo de la cantidad disponible. A diferencia de la bebida dulce o poco fermentada, el masato fuerte consumido durante las masateadas produce embriaguez ( $p a \ddot{\text { ë}}$, lo que tiene consecuencias de varios órdenes, como veremos más adelante.

Ya en el ámbito doméstico, los niños ocupan un lugar importante, pues ingieren el masato dulce cotidianamente y existe una preocupación especial para que la bebida no falte. Más que una bebida, el masato es considerado un alimento básico. Dulce o un poco amargo, el masato es bebido también por los adultos cuando realizan algún trabajo pesado, como la construcción de una canoa o durante el trabajo en la chacra. Cuando alguien necesita de la ayuda de otros para realizar alguna tarea que requiere el esfuerzo colectivo, se encarga de preparar masato para agasajar a los que partici-

\footnotetext{
${ }^{3}$ Las chacras son las áreas de cultivo, que se localizan en las proximidades de la aldea. Cada familia tiene su propia chacra.

${ }^{4}$ Sobre los yawanawa, a ese respecto, ver Carid (1999: 124). Ya entre los kaxinawa, la saliva, en este caso de los hombres, está asociada metafóricamente a la eyaculación (Lagrou 2007).
} 
pan de la minga. El masato es, por lo tanto, consumido cotidianamente en la aldea en diversos contextos. De hecho, es muy raro ver a un yaminahua beber agua, ya que lo que se bebe más frecuentemente para mitigar la sed es masato.

Sea dulce o ya fuerte, el masato es ofrecido a visitantes, mestizos, blancos ${ }^{5} \mathrm{o}$ indígenas. Con cualquiera, el masato funciona como un operador de relaciones, como invitación mediadora para el establecimiento de un contacto sociable. De hecho, es muy común que las invitaciones para subir a una casa ${ }^{6}$ yaminahua vengan acompañadas del ofrecimiento de una taza de masato. Ese acto, aparentemente banal, condensa principios básicos de la ética yaminahua como la generosidad y la hospitalidad. En ese sentido, el masato dulce constituye una especie de epítome de valores que se refieren al ámbito interno y a las relaciones de parentesco que lo constituyen: dadivosidad, prodigalidad, cuidado, ayuda mutua.

\section{Acelerando relaciones}

Lo que pueda ocurrir durante una masateada es impredecible. En el día a día, la interacción entre las personas es relativamente limitada. Esa interacción ocurre en la medida en que las personas realizan alguna actividad en conjunto o se visitan, sobre todo al final de la tarde, cuando hay un movimiento más colectivo en la aldea. Pero, en general, la cooperación y las visitas se dan entre personas especialmente próximas - entre hermanos/as, padres e hijos, marido y mujer- de forma que las familias más alejadas del núcleo central de la aldea llevan una vida más aislada. No es de extrañar, por lo tanto, que personas tan extrovertidas y amantes de la diversión como los yaminahua se tomen con regocijo la expectativa de una fiesta. Son momentos para juntarse con los parientes y encontrarse con personas con las que no se trata habitualmente o que, incluso, no viven en la aldea, como los madereros. Quiebra de la rutina, curiosidad, expectativa ante eventuales aventuras amorosas o la simple diversión, todo ello hace parte de las masateadas. Pero al mismo tiempo que el colectivo yaminahua se manifiesta como tal durante las masateadas, es también en estas ocasiones cuando las líneas de quiebra, los conflictos, en muchos casos ya latentes, se ponen en evidencia.

Varios autores han argumentado en relación a otros pueblos amazónicos ${ }^{7}$ que la vida en el interior de la aldea se caracteriza por la tranquilidad, las relaciones de cooperación y ayuda mutua, el compartir, el cuidado y la preocupación por los parientes. Como mencionamos anteriormente, la generosidad es uno de los principios éticos de los yaminahua. Pero este empeño y aprecio por el buen vivir no quiere decir que no

5 A veces, cuando el invitado es blanco, preguntan a la persona si bebe masato, ya que saben que una bebida que pasó por un proceso de masticación durante su elaboración puede no ser del agrado de todos. De hecho, los mestizos que viven a lo largo del río fabrican también masato, pero sustituyen el proceso de masticación por la adición de azúcar para facilitar la fermentación. De todas formas, aunque escuchamos algunos comentarios despectivos, especialmente por parte de mujeres mestizas, hacia la práctica de la masticación usada por las indias, nunca vimos a ningún maderero rechazar masato ofrecido por los yaminahua.

6 Las casas yaminahua son construidas sobre pilotes, como las casas de los regionales, pero, a diferencia de éstas, muchas construcciones no poseen divisiones ni paredes.

7 Ver, por ejemplo, la colección de artículos que integran el libro organizado por Joanna Overing y Alan Passes (2000). 
existan rencillas, conflictos y tensiones. Algunas son de carácter más leve, otras más serias y con consecuencias significativas. Algunas obedecen a las relaciones del día a día: infidelidades reales o supuestas, actitudes consideradas como mezquinas, celos y otros sentimientos generan enemistades de diversa intensidad y duración. Otras, conservadas en la memoria, remiten a conflictos pasados, muchas veces ni siquiera protagonizados por las personas que actualmente viven en la aldea, y pueden alimentar ciclos vindicativos de larga duración.

En lo cotidiano los eventuales sentimientos de irritación y enfado son controlados. No está bien visto que las personas se dejen llevar por arrebatos de cólera y menos aún que agredan a otras, $\mathrm{y}$ de hecho es muy raro presenciar ese tipo de comportamiento. Cuando un niño coge una rabieta, por ejemplo, la actitud más normal es una cierta indiferencia mezclada con socarronería y guasa, quedando clara la reprobación de ese tipo de actitud. Difícilmente un adulto mostrará abiertamente ira contra otra persona, y menos aún dejará que un enfado desemboque en una agresión física ${ }^{8}$.

Durante las masateadas, sin embargo, bajo los efectos embriagantes de la bebida que deja a las personas en un estado de paë, estos sentimientos de alguna forma dejan de estar bajo control. Aunque no sea la tónica general, lo cierto es que tampoco es raro que ocurran enfrentamientos, inclusive con agresiones físicas, en las masateadas. La mayor parte de los conflictos giran en torno de actitudes excesivamente celosas -los hombres se quejan de que sus mujeres los celan demasiado-e infidelidades ${ }^{9}$. Es muy común que estos conflictos desencadenados por la embriaguez tengan consecuencias posteriores. Muchas veces, escuchamos las amenazas de quienes, ya sobrios, se vieron envueltos en alguna pelea diciendo que se iban a mudar a otra aldea. De hecho fueron varias las ocasiones en las que familias, tras una masateada, trasladaron su morada a algún lugar un poco más distante -en general río abajo-, del núcleo central de la aldea. Alegando razones como que no es posible vivir junto a «borrachos que le meten a uno en problemas», que la gente de la aldea es demasiado ruidosa, o con sospechas de relaciones incestuosas, optan por un local lo suficientemente distanciado para que la interacción no sea cotidiana, pero no tan lejos como para que llegar hasta la aldea central exija un esfuerzo demasiado grande.

De cualquier modo, aunque el exceso festivo y los efectos del masato aceleran y promueven la explicitación o incluso el surgimiento de tensiones, no debemos pensar que esta facilidad para separarse es una consecuencia reciente de la introducción de una bebida alcohólica. En realidad, la dinámica social de los yaminahua siempre ha estado caracterizada por continuos movimientos de fisión y fusión de diferente alcance. En ese sentido, el masato parece funcionar como un acelerador o desencadenante de procesos estructurales en la socio-lógica yaminahua.

\footnotetext{
8 Una agresión chamánica, sin embargo, no puede ser descartada. De hecho, los yaminahua atribuyen la mayoría de estas agresiones a situaciones en que la víctima hizo que el agresor se irritase por alguna razón, principalmente por haberse comportado de forma mezquina (Pérez Gil 2006). En cualquier caso, el enfado difícilmente se demostrará abiertamente.

9 Es interesante notar que todas las infidelidades de las que tuvimos noticia se dieron entre cuñados: los hombres tienen relaciones extramaritales con las hermanas de sus esposas, que muy frecuentemente son sus primas cruzadas, categoría preferida para el matrimonio.
} 


\section{Diferencia, mestizaje y transformación}

Para los yaminahua el consumo de masato remite tanto a los cuidados entre parientes, esto es, a los principios éticos que rigen estas relaciones, como a los principios asociados a la afinidad potencial ${ }^{10}$ (exterioridad, diferencia, fertilidad). Por eso, dependiendo de las situaciones y oportunidades, extranjeros (antropólogos, mestizos, misioneros y visitantes diversos) o primos cruzados ocupan el mismo lugar estructural en las fiestas: con ellos se baila, se habla, se bromea, se flirtea. Es con ellos que se operan los principios de la alteración en diversos órdenes y es a ellos a quienes se invita especialmente. Varios aspectos remiten a esa dimensión externa de las masateadas. Los más evidentes ya fueron mencionados: la prevalencia de la tecnocumbia, que suena en radiocasetes, como estilo musical y de baile dominante; el hecho de constituir uno de los contextos privilegiados para lucir ropas y otros aderezos adquiridos en la ciudad; su celebración -no únicamente- en fechas u ocasiones que son significativas para los blancos, como las fiestas nacionales o los cumpleaños.

Pero la dimensión exterior en las masateadas alcanza también y de lleno la dinámica sociológica yaminahua, pues debe tenerse en cuenta que, actualmente, los madereros son -junto con los afines y corresidentes- el «Otro festivo» por excelencia: aquél con quien se festea, con quien es posible casarse y al cual se incorpora, eventualmente y en dosis adecuadas, a la vida aldeana, manteniéndose como un reducto de alteridad en la proximidad. Con el elemento guerrero minimizado tras el contacto, los madereros parecen ocupar funcionalmente el lugar que en otros momentos tenían, por ejemplo, los amahuaca, con los cuales mantenían un tipo de relación caracterizada como de «simbiosis guerrera» (d'Ans 1982: 268-269) o «interdependencia precaria» (Townsley 1988: 94): simultáneamente enemigos y cuñados, las relaciones entre ambos grupos oscilan desde hace décadas entre las alianzas establecidas por medio de casamientos y los conflictos, cuya principal manifestación actualmente son las acusaciones de brujería y su memoria.

En el caso de los madereros, la relación toma tintes particulares. Alianza y conflicto continúan siendo los elementos a partir de los cuales se estructura la relación; sin embargo, el punto conflictivo de la relación, lo que la hace precaria, está íntimamente ligado a aquello que la hace deseable. Para los yaminahua, una de las principales características de los «blancos» es la posesión de mercaderías; la otra particularidad que los marca es su actitud mezquina con los bienes que poseen. Simultáneamente fuente y límite en relación a los objetos, los blancos parecen constituir en sí mismos una especie de oxímoron.

La fascinación y el deseo por los objetos es algo que definió la relación con los nawa ${ }^{11}$ (extranjeros) desde su inicio, y el propio etnónimo «yaminahua» carga esa marca. Literalmente, yaminahua significa «la gente del hacha de metal»y, según nos explicaron en diferentes momentos algunas personas, les fue dado porque durante los primeros encuentros con los blancos, les pedían insistentemente yami, o sea hachas de metal. Después de oír insistentemente esa palabra, «yami, yami, yami», y pensan-

\footnotetext{
10 Para la especificación del concepto de afinidad en el espacio amerindio ver Viveiros de Castro (2002).

11 Sobre los diversos usos y sentidos del término nawa, ver Calavia (2002).
} 
do que en vez de pedir algo se estaban presentando, los blancos acabaron por darles el nombre de yaminahua.

Ropa, herramientas de metal, escopetas y perros eran los ítems más requeridos y que, antes del contacto permanente, substraían de los campamentos, primero de caucheros y luego de madereros. Actualmente el abanico de objetos deseados se ha ampliado -aparte de los anteriormente citados, podríamos añadir: linternas, implementos de pesca, utensilios de cocina, radios y cintas de música o relojes, entre otros-. A pesar de la diversidad podemos observar que todo gira principalmente en torno a dos asuntos: las actividades productivas (caza, pesca y agricultura) y la vida social (objetos de adorno y embellecimiento, fundamentalmente, o para el divertimento colectivo, como la música).

La otra cara de la moneda, el lado negativo del blanco, se refiere a la mezquindad de los nawa. Se trata de uno de los comportamientos más reprobados en términos éticos por parte de los yaminahua. Los no indígenas, especialmente algunas categorías, constituyen los paradigmas de esta actitud. No es por casualidad que el término con el que se designa al regatón -que se dedica a recorrer los ríos vendiendo mercaderías a un precio exorbitantemente superior al que tienen en las ciudades- sea yuwaxi, exactamente 'mezquino'.

Yuwaxi no es un mero adjetivo, sino que remite directamente al mezquino mítico, sobre el cual existe un conjunto de mitos, ampliamente difundido entre varios grupos pano, que narran cómo diferentes animales roban sucesivamente a la gente mezquina (Yuwaxihu) varios elementos asociados a la alimentación (fuego, maíz, pimienta, yuca) que eran monopolizados por ellos y que se negaban a ceder a otras personas, a pesar del sufrimiento que éstas pasaban a causa del hambre. Finalmente, el Yuwaxi - a veces caracterizado como un colectivo, en otras como una única persona, pero en cualquier caso epítome de la avaricia- muere a manos de la gente-pájaro que se bañan en su sangre, adquiriendo el colorido característico del plumaje de cada especie. A partir de ese momento, diferenciados, se dispersan y pierden la capacidad de comunicarse entre sí.

A los ojos de los yaminahua, la mezquindad justifica en última instancia la muerte del avaro. De hecho, desde el punto de vista de la narrativa, su muerte es en gran medida el gatillo que despliega la historia. Si, como sugiere Gow para los piro (1991), lo que constituye la historia es el parentesco, no es de extrañar que en la narrativa una situación inicial en la que el parentesco no es posible sea concebida como su congelamiento inicial, pues la mezquindad prevalece impidiendo uno de los principios en los que se basa el parentesco: la producción de alimentos.

La narrativa yaminahua parece distinguir entre el estado actual de cosas, marcado por el parentesco, la historia, el carácter discreto del conjunto de seres existentes y la fertilidad, y un estado anterior en que los humanos y no humanos todavía no habían manifestado sus diferencias entre sí, las mujeres no eran fértiles ${ }^{12}$, no había

12 Estamos haciendo aquí referencia al mito de Luna (Ushë), ampliamente expandido entre las sociedades amazónicas. En la versión yaminahua, incluidas las exégesis realizadas por Txaiyawabade, el surgimiento de Luna no sólo tiene como consecuencia que las mujeres comiencen a menstruar, o sea, que sean fértiles, sino que a partir de ese momento deberán casarse con otros (Carid 2009). Casarse fuera, por lo tanto, es la condición de posibilidad de la reproducción social yaminahua, es decir, del parentesco. 
parentesco (por falta de fertilidad, pero también por falta de alimentos) y las personas vivían en un mundo en el cual el mezquino mítico había impuesto su punto de vista. El discurso mítico revela, en otro plano, algo que también el discurso social afirma: mezquindad y parentesco -y por lo tanto historia- se oponen. Este hecho se encuentra en el núcleo de uno de los grandes dilemas de los yaminahua. Retomaremos este punto más adelante.

Pero todavía hay otra característica de las masateadas que remarca su dimensión de puente con la exterioridad. Si bien es cierto que tanto la centralidad actual del consumo del masato en la vida social yaminahua como su asociación con lo indígena podrían sugerir un vínculo nítido de esta bebida con la tradición yaminahua, lo cierto es que el propio masato, como subrayan los yaminahua, tiene su origen en el exterior. Los yaminahua, antes del proceso de contacto permanente en la segunda mitad del siglo XX y durante el periodo inmediatamente posterior al mismo, preparaban y consumían diversas bebidas de base vegetal: de maíz y de plátano, principalmente, y de yuca en menor medida ${ }^{13}$. A diferencia de lo que ocurre actualmente, en que el principal cultivo presente en las chacras yaminahua es la yuca, antiguamente predominaba el maíz. Los yaminahua y varias personas que, por diversos motivos, los conocieron en los primeros momentos de contacto definitivo coinciden en ese punto. Lo importante en relación con el consumo de estas bebidas en el periodo anterior e inmediatamente posterior al contacto es que no las dejaban fermentar. En numerosas ocasiones nos comentaron que en aquella época, cuando el chapo -bebida a base de plátano- o la chicha -a base de maíz- fermentaban, los descartaban alegando que provocaba dolor de barriga o, de forma general, «hacía mal al cuerpo». Descripciones de personas que presenciaron encuentros festivos que tenían como eje el consumo de este tipo de bebidas corroboran su carácter no-alcohólico. El padre Ricardo Álvarez, misionero dominicano que trabajaba en la Misión de El Rosario y que durante los primeros años de la década de los 60 hizo varias expediciones al Inuya y al Mapuya para contactar a los yaminahua, todavía renuentes a volver a dar ese paso ${ }^{14}$, describe una «fiesta del maíz» celebrada entre amahuaca y yaminahua en la que se consumieron grandes cantidades de chicha que no tenía contenido alcohólico. De hecho, en el

13 Aunque no nos vamos a extender aquí sobre ese asunto, cabe mencionar que los yaminahua hablan de un tipo de fiesta, que ya no es celebrada, llamada wamitine. En el wamitine encontramos varios de los elementos que caracterizan a las masateadas: se trataba de ocasiones que juntaban familias que vivían en malocas dispersas, contando a veces con la participación de otros grupos, como los amahuaca; giraban en torno a una bebida de base vegetal, principalmente de plátano o de maíz, pero no fermentada; aparte de beber, se cantaba y se bailaba; las personas se arreglaban, usando pinturas y ornamentos; era un contexto en el que las relaciones entre géneros, y la eventualidad de las aventuras sexuales, estaban en primer plano, lo cual se evidenciaba en el contenido erótico de algunas canciones. Divertimento, musicalidad, presencia de la alteridad, fertilidad y exhibición de generosidad son aquí también los pilares de la fiesta. Parece, a partir de las descripciones con las que contamos, que estaban especialmente asociadas a momentos de cosecha de frutos de la chacra. Una descripción de una fiesta análoga entre los amahuaca aparece en Huxley y Capa (1964).

14 Debe aclararse aquí que lo que denominamos contacto no fue un momento específico sino un proceso que demoró varias décadas. En algunos momentos, a medida que los frentes de ocupación de la Amazonía alcanzaban los territorios por donde circulaban, los yaminahua intentaron establecer relaciones amigables sin mucho éxito. En otras ocasiones, fueron los blancos los que, en busca de mano de obra para la extracción del caucho o la madera, tomaron la iniciativa, siendo las ofertas rechazadas por los yaminahua, escarmentados por anteriores experiencias. 
mismo pasaje, el padre se refiere a una anécdota que le narraron los yaminahua: en una ocasión bebieron hasta emborracharse con el licor robado de un batelón brasileño y «borrachos, adquirieron una experiencia que no tenían: se pelearon unos contra otros, golpeándose las nucas, no las caras, viéndose, al despertar, enfermos, sin poder mover sus cabezas» (Álvarez 1998: 104-105). Como nos contaron, tan sólo había un contexto muy específico durante el cual se consumía bebida fermentada de maíz o de banana: el ritual de escisión de clítoris de las jóvenes. En ese caso, la chicha era utilizada para emborrachar a las muchachas que se someterían a la dolorosa operación con la finalidad de que pudieran aguantarla (Pérez Gil 2006: 144-146).

Este rechazo explícito, en la era pre contacto, a las bebidas fermentadas contrasta con el entusiasmo y la fruición con las que los yaminahua se dedican hoy en día a las masateadas. El entusiasmo es tal que sorprende incluso a aquellos que en la región se tienen como los grandes consumidores tradicionales de masato, de quienes los yaminahua, como ellos mismos cuentan, aprendieron la costumbre (Pérez Gil 2011). En su etnografía sobre los ashaninka, Lenaerts comenta que «el masato aparece hoy en día como uno de los rasgos culturales más típicos de los yaminahua ('ellos lo fabrican en grandes cantidades y muy alcoholizado', dicen los ashéninka)» (Lenaerts 2002: 335).

Fue precisamente con los ashaninka con quienes los yaminahua aprendieron a fabricar y a beber masato: en las narrativas que explican como ocurrió el proceso que los llevó a establecer relaciones permanentes con los nawa, el masato y los ashaninka tienen un papel fundamental. El siguiente relato es parte de la explicación de Txaiyabawade sobre ese proceso.

«Estando allí (en Cuchillo, una quebrada del Mapuya), han bajado a su chacra ${ }^{15}$. Allí empezó a morir el padre de Txaiyabawade y ellos se desesperaron: ‘¿Dónde vamos a vivir ahora?'. Y decidieron bajar más, hasta Capirona. ‘¿Qué vamos a hacer? Hay que encontrar a alguien que nos dé machete'. Fueron por otro sitio ${ }^{16}$. Allí encontraron a los campa, que estaban civilizados, pero eran pobres como ellos. 'Hay que matarlos', decían algunos. 'No, vamos a ver qué hacen'. Los campa estaban bebiendo masato. Txaiyabawade y otro hombre se escondieron y cuando pasó un campa Txaiyabawade lo agarró para llevarlo a su casa. El campa comenzó a gritar: 'no me mates, no me mates'. Esos campa no tenían nada, su cusma estaba podrido, tomaban masato en pote. Cuando vieron que habían agarrado al hombre, el resto de los campa corrieron al monte. $\mathrm{Su}$ paisano ${ }^{17}$ mismo los llamó para que volvieran: 'no corráis, no me van a matar'. ‘¿Por qué corren ustedes? Yo no les voy a matar. Yo no soy animal para matarles a ustedes. Yo sólo mato animal para comer', decía Txaiyabawade. Se quedaron allá parados. 'No me maten'. Ya les dieron masato en pote. Nunca habían tomado masato los yaminahua, estaba fuerte. Lo aceptaron y comenzaron a conversar. Txaiyabawade tenía un peque-

15 Este relato fue narrado por Txaiyabawade en yaminahua y traducido por su hijo, por eso Txaiyabawade no aparece como el narrador, sino como un personaje al que su hijo se refiere en tercera persona.

16 Txaiyabawade no se refirió al lugar exacto, pero otras personas que relataron el mismo episodio lo situaron en el Huacapistea, un pequeño río que afluye al Yuruá. Debemos recordar que los yaminahua durante, por lo menos el último siglo -o sea, desde que se tienen las primeras noticias sobre ellos- han estado circulando por la región en la que confluyen las cabeceras de los ríos Yuruá, Purus y Mapuya, este último afluente del Ucayali. Precisamente por ser una región de cabeceras de río es de difícil acceso, posibilitando que los yaminahua se mantuviesen en relativo aislamiento de los blancos hasta el primer cuarto del siglo XX.

17 Con este término, se refieren en la Amazonía peruana a quien pertenece al mismo grupo étnico. 
ño machete; los campa no tenían y se lo pidieron. 'No puedo darlo, tengo que hacer mi chacra', les decía Txaiyabawade.

- ‘Dónde lo has conseguido?'.

- 'Allá en el Mapuya'.

- ‘Es lejos de aquí?’'

- 'No, es cerca ¿y Brasil?'.

- 'Es por ahí abajo'».

Las masateadas se caracterizan por el exceso. Si los yaminahua pueden reunirse por otros motivos, cuando los médicos visitan la aldea para las vacunaciones, para realizar algún trabajo colectivo (minga) o recibir alguna visita, de curas o antropólogos, por ejemplo, la verdad es que sólo ante un evento muy extraordinario se reunirían varios días, como sucede en estas fiestas cuando se dispone de bebida abundante. Exceso de masato, que debe ser ingerido abundantemente, hasta la embriaguez; exceso de hablas que se entremezclan en el típico ruido continuo que caracteriza a estas reuniones; de ropas y adornos de la ciudad, que les hace verse más acicalados (pitucos, se dice allí) de lo que suelen estar en el día a día; de bailes y músicas; de bromas y jocosidades, que ahora pasan a formar parte del espacio colectivo. El exceso envuelve la fiesta y da el tono a la reunión. Así, si en el día a día el alimento se reparte según líneas de intercambio y generosidad concretas; las relaciones con los madereros son mediadas por el trabajo, por el pago o la deuda; el espacio se fragmenta en función de las unidades familiares, sus diferentes accesos al río, sus patios, etc., durante las masateadas asistimos a las relaciones mediadas por la generosidad indiscriminada, con parientes cercanos, con afines y con extranjeros. El exceso festivo permite en cierto sentido ser como el otro.

En ese sentido, los yaminahua asocian las masateadas al proceso civilizatorio en el que, según ellos mismos consideran, se hallan inmersos. Pero, ¿qué significa «civilizarse» para los yaminahua? Como bien apunta Gow al respecto de los piro, la civilización adquiere significados específicos en los contextos indígenas, no necesariamente coincidentes con los nuestros. El punto resaltado por Peter Gow es que para los piro ser civilizado no se opone a ser nativo. No se trata de categorías excluyentes. Es civilizado quien tiene acceso y consume bienes manufacturados que circulan a través del sistema de habilitación ${ }^{18}$. Según esa acepción, el grado de civilización depende de la cantidad y calidad de bienes que se consumen y, en ese sentido, los piro son diferentes y superiores a los indios salvajes. Por otro lado, a pesar de que los blancos se muestran superiores a ese respecto, hay otro aspecto que sitúa a los

18 Este sistema, que constituye en gran medida la estructura socioeconómica de la región, se basa en la relación entre el patrón y el habilitado. El primero presta recursos al segundo, generalmente en forma de objetos manufacturados, a cambio de que éste se encargue de explotar algún tipo de recurso natural (en su momento el caucho, actualmente la madera, principalmente). Con el fruto de ese trabajo pagará las mercancías dadas como adelanto. Uno de los puntos básicos de la relación es que los habilitados permanecen encadenados al patrón por medio de una deuda prácticamente imposible de cancelar. Mientras los objetos manufacturados -que en su mayor parte son necesarios para la realización del propio trabajo- dados al inicio representan un montante mucho mayor a su valor de mercado, el precio pagado al habilitado por la materia prima extraída es muy bajo. La relación asimétrica entre patrón y habilitado funciona como una especie de átomo del sistema, ya que se va repitiendo de forma fractal: todo habilitado habilita a otros, con los recursos recibidos, $\mathrm{y}$, por ende, todo patrón tiene un patrón. 
piro en una posición de superioridad moral: comen «alimentos legítimos» (cultivados por ellos mismos en la chacra) y viven conforme a los valores del parentesco (Gow 1991). Tanto el ser civilizado como el ser nativo son cualidades inherentes a los piro actuales y la articulación entre esos dos aspectos los diferencia tanto de los blancos como de los salvajes.

¿Y para los yaminahua? En una ocasión, un yaminahua tradujo civilizar como usĩ, que literalmente significa «mezclarse». El comentario fue hecho en un contexto en el que nuestro interlocutor hacía referencia a la frecuencia con que, en la actualidad, se producen matrimonios entre yaminahua y ashaninka o mestizos ${ }^{19}$. Mezclarse con determinados tipos de otros -básicamente ashaninka y mestizos, pero no, por ejemplo, amahuaca, con los que tradicionalmente los yaminahua se han casado- es entendido como un mecanismo de civilización. Como resalta el relato anterior, los ashaninka son buscados por los yaminahua para operar como mediadores en el establecimiento de relaciones con los blancos. Además, son concebidos como la fuente de varios ítems o prácticas culturales característicos, a ojos yaminahua, del período posterior al contacto. Es importante aclarar que aunque la idea de civilización, al igual que en el caso piro, está fuertemente asociada al acceso y consumo de bienes manufacturados, éstos no son los únicos elementos que la constituyen: la primacía del cultivo de la yuca, la celebración de masateadas o el uso de esteras para dormir ${ }^{20}$ son, entre otros, aspectos ligados a ella.

Pero las masateadas no son sólo índice de civilización, sino también un medio para civilizarse. Aparte de los significados que asocian al masato con la exterioridad y con el proceso de contacto, opera aquí una lógica alimentaria ${ }^{21}$. Lo que se ingiere tiene la capacidad de producir modificaciones corporales por el contagio de sus propiedades. Esto es especialmente patente en determinados momentos de la vida de las personas. En ocasiones, las situaciones de transformación corporal se derivan del propio desarrollo vital de las personas, como las modificaciones somáticas que ocurren durante la adolescencia o durante el embarazo; en otras, son provocadas de forma intencional a través de la introyección de algún elemento portador de agencia, como pueden ser las diferentes substancias chamánicas -la ayahuasca, el tabaco, excreciones corporales de la boa, el veneno de las avispas, la sangre del enemigo...-. En cualquier caso, la persona en este estado debe controlar rigurosamente lo que come, para poder adquirir -incorporar en el sentido más literal de la palabra- las cualidades buscadas -el poder

19 El comentario de Manate podría hacer parecer que, efectivamente, existiría una tendencia actual a casarse con mestizos o ashaninka, pero, si se consideran las cifras, este tipo de matrimonio, especialmente con ashaninka, es bastante raro. Continúan predominando los matrimonios entre yaminahua. La poca querencia a casarse con ashaninka -no así con mestizos - coincide con una cierta tradición yaminahua: para la época anterior al contacto, aunque tuvieron diversos enfrentamientos con los ashaninka, no hay prácticamente referencias de raptos de mujeres de este origen. Eso contrasta, de un lado, con el hecho de que las mujeres yaminahua sí eran raptadas por los ashaninka, y, por el otro, con la frecuencia de rapto de mujeres amahuaca. Todo parece indicar que existía una exogamia local, pero una endogamia lingüística que tornaba a las mujeres ashaninka poco deseables. Tanto antiguamente como ahora el índice de matrimonios con ashaninka es bajo. La diferencia ahora es que los ashaninka adquirieron un valor simbólico como agentes, desde el punto de vista yaminahua, de civilización.

20 Actualmente, los yaminahua duermen en el suelo sobre esteras y protegiéndose con mosquiteros, pero antes del contacto lo hacían en hamacas hechas de fibras vegetales.

21 Para una descripción y análisis más detallados de esta lógica, ver Pérez Gil (2010). 
chamánico, por ejemplo, o la puntería y la destreza en la caza- y evitar desarrollar atributos indeseados, como debilidad, indolencia, corpulencia excesiva, delgadez. Dentro de esta lógica, aunque sin la necesidad de que la persona se encuentre en un estado de transformación corporal específico, los alimentos de los nawa tienen la peculiaridad de neutralizar y destruir el poder chamánico. Este efecto de los alimentos nawa es muy explícito en el discurso yaminahua, y de hecho los más viejos ven en ello, con un cierta nostalgia crítica, la causa de la decadencia de sus congéneres. Dentro del conjunto de alimentos que tienen este efecto sobre los cuerpos yaminahua, se encuentra el masato.

En otro lugar (Pérez Gil 2006), propusimos que la evitación de las bebidas fermentadas antiguamente se debía a su interferencia directa en el poder chamánico, que, en mayor o menor grado, la mayor parte de los hombres, y algunas mujeres, se esforzaban por adquirir. La actual pasión de los yaminahua no tanto por el masato sino por las masateadas debe ser entendida en función de este proyecto ontológico: hace referencia al actual proyecto de muchos yaminahua de «volverse mestizo». Como nos explicaba una mujer mientras hablábamos sobre los ornamentos usados antiguamente por los yaminahua pero que, hoy en día, sólo algunos de los viejos continúan exhibiendo, ella ya no va a agujerear el labio y las orejas de sus hijos porque ahora van a ser mestizos. Durante las masateadas los yaminahua se comportan como-y, por lo tanto, son como-nawa. En su dimensión ritual, las masateadas no son, por tanto, reservatorios de identidad o tradición y sí momentos propicios para la invención (Calavia 2004) y la construcción de modos de ser, que no por ello son menos yaminahua, pues son realizados justamente por ellos.

Sin embargo, para no naturalizar esa afirmación, deberíamos preguntarnos qué es lo que significa para los yaminahua «ser mestizo». Con seguridad no se refiere a lo que nuestra lógica culturalista considera en términos de «pérdida cultural» o de contaminación y degradación de tradiciones. Según ese punto de vista, para adquirir una cultura diferente, se tiene que perder previamente la propia o se la tiene que contaminar con aquella que se quiere adquirir, dando como resultado un derivado degradado, impuro y poco apreciado que no es ni una cosa ni la otra ${ }^{22}$. Para los yaminahua devenir mestizo escapa a la interpretación occidental del Ser que impele a ser uno u otro, quizás porque para los yaminahua el ser como identidad no define el ser, ni este pasa necesariamente por la unidad ${ }^{23}$.

Desde el punto de vista yaminahua, «ser mestizo» parece ser entendido, más bien, como «tener las capacidades de nawa» ${ }^{24}$, o mejor aún, «tener ciertas capacidades

22 La estética occidental y la interpretación convencional del mestizaje cultural quizás derive de lo ya señalado por Mary Douglas al respecto de otras cuestiones: la transgresión de fronteras entre categorías es percibida como desorden, y el desorden remite a la impureza (Douglas 1991). Como afirma Gruzinski (2007: 48), el propio concepto de mestizaje lleva implícito el concepto de lo puro, de forma que necesitamos desconfiar, como de la peste, de las connotaciones y apriorismos acarreados en la idea de mezcla.

23 No podemos extendernos sobre ese punto aquí. Para una discusión sobre la multiplicidad yaminahua relacionada con las nociones de persona e identidad ver Carid 2007a.

24 Según esta lógica, el cuerpo, más que una fisiología distintiva o una morfología fija, es un conjunto de afecciones y capacidades, de modos de ser que constituyen un habitus (Viveiros de Castro 1996). 
de nawa». Si los yaminahua ansían claramente ser «ricos» $\rangle^{25}$ como los nawa, en el sentido de tener la capacidad de adquirir bienes, este deseo encuentra sus límites en las críticas éticas que el comportamiento de los nawa despiertan: la posesión y acumulación de bienes asociada a la avaricia. El riesgo de ser mezquino, especialmente con los parientes, es posiblemente el principal obstáculo en ese proyecto de devenir mestizo, que se constituye más en un horizonte al que se tiende pero al que no se llega $y$, en cierto sentido, al cual no se quiere llegar totalmente. El querer ser mestizo se ve matizado en función del oxímoron que representa para los yaminahua ese modo de ser: propietario de algo que se desea, pero epítome de un modo de ser sobre el que se tienen restricciones éticas ineludibles.

\section{Memorias intensas y extensas}

Si bien es cierto, como hemos examinado en las páginas anteriores, que en cuanto mecanismo a través del cual se favorece una comunicación en varios registros con el 'otro', los yaminahua se proyectan hacia el exterior y lo introducen en el espacio aldeano, también es cierto que el exterior yaminahua no es un todo fácilmente reductible, habitado apenas por la alteridad y las potencialidades de la afinidad, por espíritus, enemigos, blancos, indígenas de otras etnias, primos o cuñados. Una cierta tendencia a la exogamia local y a los constantes procesos de fusión y fisión provoca la fragmentación de los núcleos familiares tejiendo una red de relaciones que excede el espacio aldeano, pues las relaciones se fragmentan pero no se interrumpen. Así, en el exterior se encuentran también los parientes: hermanos, hermanas, padres, abuelos, etc.

De hecho, durante mucho tiempo tuvimos la sensación de que existían dos tipos de yaminahua: aquellos con quienes vivíamos en Raya, que conocíamos, y aquellos de los cuales nos hablaban, fuesen estos los parientes ya fallecidos o los que habitan en otras aldeas, en las comunidades del Yuruá principalmente. Esos yaminahua exteriores de los cuales nos hablaban, eran descritos de una forma que los hacía parecer como más interesantes, una especie de versión mejorada de nuestros anfitriones de Raya. Por eso, cuando viajamos al Yuruá para conocer a los yaminahua del «otro lado», como se refieren a ellos en Raya, la sensación era justamente la de estar adentrándonos en una realidad social vigorosa y exuberante, de tanto que habíamos oído hablar (y cantar) de ellos y en términos tan formidables.

Tal vez no sea un detalle irrelevante que para cerrar nuestra estancia más larga en Perú, y a pesar de la dificultad logística que suponía llegar hasta allí, nos lanzáramos a visitar el Yuruá durante un mes. Percibido intuitivamente en aquel momento, vemos claro ahora que ese trabajo de campo fue dado por la importancia que el «otro lado» tenía para los propios yaminahua. El «estar allí», en Raya, debía pasar obligatoriamente por el Yuruá. Con nuestro viaje, en realidad, tan sólo estábamos confirmando esa evidencia etnográfica que se manifestó repetidamente cuando vivimos en el Mapuya: el «otro lado» y «este lado» forman figura. Para conocerla era necesario viajar.

25 Ser rico adquiere, en el caso de los yaminahua, un sentido claramente asociado a la acumulación, sea de objetos o de otros bienes. 
Una de esas manifestaciones donde esa figura se hizo reconocible fue en las músicas yama yama, que pudimos oír varias veces durante las masateadas ${ }^{26}$. Fue justamente a partir de nuestra familiarización con estos cantos y de los viajes de los propios yaminahua, anunciados incansablemente y realizados efectivamente de vez en cuando, que esa conexión se hizo más evidente.

Los yama yama narran la memoria de la separación, se dirigen a los parientes que no se encuentran junto a quien los interpreta, sea porque ya murieron o porque viven en otras aldeas. Son músicas cantadas individualmente tanto por hombres como por mujeres, sin acompañamiento de instrumentos musicales y sin baile que las acompañe. Son fácilmente reconocibles porque los cantos tienen patrones melódicos, prosódicos, narrativos y semánticos concretos.

Pero lo que nos interesa tratar aquí no es tanto los cantos en sí como su contexto, ya que muchas veces en medio de la fiesta, o incluso después de haber concluido la reunión, alguna persona iniciaba el canto recordando a esos parientes ausentes. Si bien al principio desconocíamos el significado de los cantos, que por su nivel de condensación y lenguaje propio resultan de difícil traducción hasta para los yaminahua, cuando pudimos comprobar que eran músicas asociadas a la memoria y a la melancolía (xinai bitsai), que narraban recuerdos de corresidencia con parientes que ya no estaban presentes, algo nos pareció fuera de contexto, pues ¿no se caracterizan las masateadas por la alegría y la jocosidad, por su trato festivo con el otro ${ }^{27}$ ?

\section{Conclusiones}

Las masateadas son momentos durante los cuales las familias yaminahua se manifiestan como colectividad, o dicho de una forma más adecuada a este tipo de fiestas: reunidos en torno al masato no se puede no comunicar ${ }^{28}$. No se trata aquí de una colectividad asumida como identidad colectiva o cosificada institucionalmente, pues en realidad, como vimos, la reunión lleva justamente, y al mismo tiempo, a la introyección del otro y a la memoria individual de los parientes que ya no viven en la aldea. Se trata, en realidad, de un doble proceso de alteración en dirección hacia fuera, pero hacia un afuera poblado tanto por figuras de la alteridad como del parentesco.

En las masateadas esos procesos se evidencian de forma condensada, simultánea y en acción. Esa escena que pudimos presenciar varias veces durante las masateadas, cuando muchos yaminahua bailan con sus afines o con los mestizos al ritmo de la tecnocumbia, cuando otros conversan y beben masato y otros cantan yama yama recordando a algún pariente, ejemplifica y hace percibir, stricto sensu, el carácter intrincado de la socialidad yaminahua.

26 Como las masateadas es el tema central de este artículo, no desarrollaremos aquí la descripción o el análisis de los yama yama. Para trabajos más extensos sobre esos cantos yaminahua de la Amazonía peruana y brasileña ver Carid (2007a, 2007b) y Calavia (2006).

27 Sin embargo, los yaminahua no son una excepción. Los judjá reúnen también en las fiestas manifestaciones estructurales de alegría y tristeza (Lima 2005).

28 «One cannot 'not communicate'» es una frase de Paul Watzlawick, integrante del grupo de Palo Alto. 
De hecho, si hay algo que caracteriza las masateadas à la yaminahua es la composición de ese escenario múltiple: por un lado, el masato es ofrecido por las mujeres a los hombres y mujeres que participan de la reunión, reinando la jocosidad, la confusión de voces, el baile, las provocaciones amorosas, el intercambio con afines, madereros y visitantes. En ese sentido, las masateadas remiten a los complejos festivos amerindios de las reuniones entre afines y de contacto mediado con la exterioridad; por otro lado, las músicas yama yama, los lloros, los recuerdos vehiculados en los proyectos de cambiarse de aldea, que remiten al parentesco y a la familia. Se canta yama yama porque se está borracho, porque se está pensando, dicen los yaminahua, y es en las fiestas que esa ocasión se presenta con mayor intensidad.

Es en ese sentido, en cuanto momentos que articulan y manifiestan sus elementos centrípetos y centrífugos, en el que las masateadas condensan el modo social de ser yaminahua. Por ello también, no deja de ser paradójico que las masateadas se constituyan en los mecanismos privilegiados por los yaminahua para transformarse en Otros. O quizás no lo sea tanto. Si, como sabemos, las condiciones de reproducción social en la Amazonía -y como vimos los yaminahua son explícitos a este respectopasan por la captura e integración, o familiarización de exterioridad (Fausto 1999), o por su seducción (ver el texto de Lagrou en este dossier), ya sea de personas (Menget 2001), de cantos y nombres del enemigo (Viveiros de Castro 1986), o bienes y riquezas (Gordon 2006), lo que los yaminahua parecen estar capturando del exterior son determinadas capacidades o modos de ser. La incorporación de aspectos externos lleva a la alteración. Pero ese baño de alteridad y ese proyecto de volverse otro provocan la memoria de la separación de los parientes que viven lejos. Junto a esa estructura de intercambios, excesos y alteridades caracterizadas por la alegría y la acción, el canto lírico e individual retiene una poética del parentesco elaborada en el pensamiento y en los cantos, y direccionada para un exterior que continua siendo en realidad su centro.

\section{Referencias bibliográficas}

Álvarez Lobo, Ricardo

1998 Sepahua, V: Campo de Misión. Lima: Misioneros Dominicos.

Calavia Sáez, Óscar

2002 «Nawa, Inawa». Ilha. Revista de Antropologia 4 (1): 35-54.

2004 «In Search of Ritual: Tradition, Outer World and Bad Manners in the Amazon». Journal of the Royal Anthropological Institute 10 (1): 157-173.

2006 O nome e o tempo dos Yaminawa: etnologia e história dos Yaminawa do rio Acre. São Paulo: Ed. da UNEP - ISA - NUTI.

CARID, Miguel Alfredo

1999 Yawanawa: da guerra à festa. Tesis de Maestría, Universidade Federal de Santa Catarina.

2007a «A memória biográfica dos Yaminahua e a quarta dimensão do social», en Donos da palavra: autoria, performance e esperiência em narrativas orais na América do Sul, Fernando Fishman y Luciana Hartmann, eds., pp. 67-94. Santa Maria, RS: Ed. da UFSM. 
2007b Yama yama: os sons da memória. Afetos e parentesco entre os Yaminahua. Tesis de Doctorado, Universidade Federal de Santa Catarina.

2009 «Imagens dos Yaminahua», en Faces da Indianidade, Maria Inês Smiljanic, José Pimenta y Stephen G. Baines, eds., pp. 235-243. Curitiba: Nexo Design.

D'Ans, André-Marcel

1982 L'Amazonie péruvienne indigène. París: Payot.

Douglas, Mary

1991 Pureza y peligro. Un análisis de los conceptos de contaminación y tabú, $2^{\mathrm{a}}$ ed. Madrid: Siglo XXI.

Fausto, Carlos

1999 «Of Enemies and Pets: Warfare and Shamanism in Amazonia». American Ethnologist 26 (4): 933-956.

GoRDON, Cesar

2006 Economia selvagem. Ritual e mercadoria entre os indios Xikrin-Mebêngôkre. São Paulo: ISA - Ed. da UNESP - NuTI.

Gow, Peter

1991 Of Mixed Blood. Kinship and History in Peruvian Amazonia. Oxford: Clarendon Press.

GRUZINSKI, Serge

2007 El pensamiento mestizo. Cultura amerindia y civilización del Renacimiento. Barcelona: Paidós.

HuxLey, Matthew y Cornell CAPA

1964 Farewell to Eden. Nueva York: Harper \& Row Publishers.

LAGrou, Els

2007 A fluidez da forma: arte, alteridade e agência em uma sociedade amazônica [Kaxinawa, Acre]. Río de Janeiro: Topbooks.

LENAERTS, Marc

2002 Nos soeurs Manioc et l'étranger Jaguar : diversité et changement des savoirs sur les Etres de la Nature, chez les Ashéninka « de l’Ucayali «(Amazonie péruvienne et brésilienne). Tesis de Doctorado, Université Libre de Bruxelles.

LiMA, Tânia Stolze

2005 Um peixe olhou para mim: o povo Judjá e a perspectiva. Río de Janeiro: UNESP.

MeNGET, Patrick

2001 Em nome dos outros. Classificações das relações sociais entre os Txicáo do Alto Xingu. Lisboa: Assírio \& Alvim.

Overing, Joanna y Alan PAsses, eds.

2000 The Anthropology of Love and Anger. The Aesthetics of Conviviality in Native Amazonia. Londres: Routledge.

PÉRez Gil, Laura

2006 Metamorfoses Yaminawa: Xamanismo y socialidade na Amazônia Peruana. Tesis de Doctorado, Universidade Federal de Santa Catarina.

2010 «Cuerpos en transformación: sobre la noción de persona y el control alimentar entre los Yaminawa». Tellus 10 (19): 53-82. 
2011 «Adversários e mediadores: os outros dos Yaminawa no processo de contato», en Os Outros dos Outros: Relações de alteridade na Etnologia Sul-Americana, Edilene Coffaci de Lima y Lorena Córdoba, eds., pp. 83-94. Curitiba: Ed. da Universidade Federal de Paraná.

TownSLEY, Graham

1988 Ideas of Order and Patterns of Change in Yaminahua Society. Tesis de Doctorado, Cambridge University.

Viveiros de CAstro, Eduardo

1986 Araweté, os deuses canibais. Río de Janeiro: Jorge Zahar-ANPOCS.

1996 «Os pronomes cosmológicos e o perspectivismo ameríndio». Mana 2 (2): 115144.

2002 «O problema da afinidade na Amazônia», en A inconstância da alma selvagem e outros ensaios em antropologia, pp. 87-180. São Paulo: Cosac \& Naify. 